www.volsu.ru

\title{
TRANSLATION OF POLYSEMOUS AND SYNONYMOUS TERMS OF THE ENGLISH LANGUAGE: THE POSSIBILITIES OFA COGNITIVE APPROACH
}

\author{
Irina B. Rubert \\ Saint Petersburg State University of Economics, Saint Petersburg, Russia \\ Svetlana V. Kiseleva \\ Saint Petersburg State University of Economics, Saint Petersburg, Russia \\ Marina Yu. Mironova \\ Saint Petersburg State University of Economics, Saint Petersburg, Russia
}

\begin{abstract}
The article describes the problem of translating polysemantic and synonymous investment terms and is studied from the perspective of cognitive linguistics, namely in the light of the prototypes theory, which presupposes the identification of the content core as the best representative of the word's semantics. The subject of the research are the semantic processes taking place in the English term system reflecting investment activity. By the example of the research of term dealer and its synonyms broker and agent, the authors have defined that the meanings of polysemantic and synonymous terms are not isolated, but are united by a meaningful core and develop according to the laws of semantic derivation based on the common language nominative-non-derivative meaning. The authors found that the reduction of translation failures in the transfer of terms is possible due to the competent use of the cognitive context and the correct definition of the content core of the terminological unit. The research is carried out by means of such methods as the prototypical semantics method, a definitional and component analysis. When identifying the content core of a polysemantic term it is first of all necessary to define the average primary meaning of this term on the basis of dictionary definitions. As a result, the most frequent meaning is determined. Then etymological analysis of the meaning is carried out. At the next stage, in order to model the cognitive image of a word, contextual analysis is performed, and metaphorical comparisons are investigated. Based on the obtained data, a content core of the term is formulated generalizing all the derived meanings and demonstrating their connections. The results obtained allow the authors to prove that the meanings of polysemantic and synonymous terms are connected by a single content core and are developed on the basis of a common linguistic meaning. The practical value of the scientific research is in the possibility to use the results of the work in lexicographic practice when compiling terminological dictionaries, and when writing university courses in terminology and translation studies. The identification of a content core is necessary while translating polysemantic and synonymous terms, because it reveals the meaning of the term in the context and defines the choice of a right translation variant.
\end{abstract}

Key words: content core, prototype, semantic components, polysemy, synonymy, term, translation, equivalent.

Citation. Rubert I.B., Kiseleva S.V., Mironova M.Yu. Translation of Polysemous and Synonymous Terms of the English Language: The Possibilities of a Cognitive Approach. Vestnik Volgogradskogo gosudarstvennogo universiteta. Seriya 2. Yazykoznanie [Science Journal of Volgograd State University. Linguistics], 2021, vol. 20, no. 4, pp. 170-181. (in Russian). DOI: https://doi.org/10.15688/jvolsu2.2021.4.14

\section{ПЕРЕВОД МНОГОЗНАЧНЫХ И СИНОНИМИЧНЫХ ТЕРМИНОВ АНГЛИЙСКОГО ЯЗЫКА: ВОЗМОЖНОСТИ КОГНИТИВНОГО ПОДХОДА}

\author{
Ирина Борисовна Руберт
}

Санкт-Петербургский государственный экономический университет, г. Санкт-Петербург, Россия 
Светлана Владимировна Киселева

Санкт-Петербургский государственный экономический университет, г. Санкт-Петербург, Россия

\section{Марина Юрьевна Миронова}

Санкт-Петербургский государственный экономический университет, г. Санкт-Петербург, Россия

Аннотация. Статья посвящена проблеме перевода многозначных и синонимичных терминов, рассматриваемой в русле когнитивной лингвистики, а именно в свете теории прототипов, согласно которой содержательное ядро аккумулирует необходимые и достаточные для понимания значения слова компоненты. Предметом исследования выступают семантические процессы, которые происходят в англоязычной терминологической системе, отражающей инвестиционную деятельность, и оказывают влияние на выбор переводческих соответствий. Исследование проведено с применением предложенной С.В. Киселевой методики, опирающейся на прототипический, дефиниционный и компонентный анализ. На примере термина dealer и его синонимов broker и agent, анализ которых осуществлен И.Б. Руберт и М.Ю. Мироновой, показано, что значения многозначных и синонимичных терминов не изолированы, а объединены содержательным ядром и развиваются по законам семантической деривации на основе общеязыкового номинативно-непроизводного значения. Авторами установлено, что снижение переводческих неудач при передаче терминов возможно благодаря грамотному использованию когнитивного контекста и правильному определению содержательного ядра терминологической единицы. Материал и результаты проведенного исследования могут быть использованы при составлении терминологических словарей и формировании университетских курсов по терминоведению и переводоведению.

Ключевые слова: содержательное ядро, прототип, семантические компоненты, полисемия, синонимия, термин, перевод, эквивалент.

Цитирование. Руберт И. Б., Киселева С. В., Миронова М. Ю. Перевод многозначных и синонимичных терминов английского языка: возможности когнитивного подхода // Вестник Волгоградского государственного университета. Серия 2, Языкознание. - 2021. - Т. 20, № 4. - C. 170-181. - DOI: https://doi.org/10.15688/ jvolsu2.2021.4.14

\section{Введение}

Коммуникативная деятельность человека является неотъемлемой частью его профессиональной деятельности. Это во многом определяет особенности процессов номинации. Говоря о терминологии, необходимо отметить, что «собственно научные термины не идентифицируются вплоть до Средневековья и появляются в английском языке в основном благодаря переводам с латинского» [Руберт, 1998, с. 25]. Тем не менее это не означает, что в более ранних текстах отсутствуют функционально терминологичные лексические единицы. На примере различных типов текстов можно наблюдать процесс формирования терминосистем: от использования единицы в текстах разных жанров через терминологизацию до специализации, когда единица закрепляется за определенными профессиональными контекстами.

Несмотря на то что сегодня существует немало исследований терминов и терминосистем различных областей (см., например:
[Бурдина, 2021; Галактионова, 2021; Миронова, Киселева, 2020а; 2020б]), освещение когнитивных аспектов функционирования терминосистем по-прежнему остается актуальным. Изучение терминологических систем как сложных иерархических образований с использованием когнитивного семантического подхода позволяет охарактеризовать глубинные процессы их формирования и функционирования.

Такое свойство терминологических единиц, как системность, предопределяет возможность развития терминологической полисемии и синонимии, которые связаны с необходимостью номинации сходных объектов научного знания. При проведении исследования в рамках когнитивного подхода следует опираться на антропоцентричность мышления, изучать лексико-семантические варианты слова и проводить работу по определению его содержательного ядра [Киселева, 2010, c. 307]. Употребляя многозначное слово носитель языка наделяет его дифференциальными оттенками смысла. При этом существую- 
щее разнообразие не выходит за пределы определенных границ, что позволяет говорящим формировать значения, связанные с содержательным ядром слова. В связи с этим в качестве важного признака содержательного ядра слова можно назвать способность сужать семантические компоненты до необходимого для коммуникантов минимума, благодаря чему «значение слова становится максимально узнаваемым при допустимой субъективности суждения» [Киселева, 2009, с. 84].

Полисемия термина имеет место в том случае, когда в его семантической структуре главная сема сохраняется, а второстепенные расходятся [Гринев, 1990, с. 97]. Многозначный термин - это термин, обозначающий разные денотаты или понятия, относящиеся к одной сфере знания и имеющие общие семы в значениях.

Способность термина как лексической единицы естественного языка иметь более одного значения влияет на процесс перевода и усложняет его. Сегодня вопросы, связанные с выявлением когнитивного основания стратегий перевода, а также когнитивной сущности переводческих ошибок, привлекают внимание многих исследователей (см., например: [Воюцкая, 2018; Колесников, 2018; Алексеева, 2006]). Когнитивные процессы дифференциации значений оказывают большое влияние на выбор правильных переводческих соответствий, поскольку именно когнитивная система переводчика как интерпретатора знаний определяет задействованные в процессе перевода ментальные операции. Переводчик выполняет функцию селекции и оценки изложенных в исходном тексте событий и выбирает способы их передачи в тексте перевода. Когнитивная семантика требует от переводчика выхода за рамки лексических значений слов в область энциклопедических знаний о мире. Согласно основным положениям теории языковой интерпретации, «язык выполняет, наряду с когнитивной и коммуникативной, интерпретирующую функцию» [Болдырев, 2018, c. 35]. В связи с этим результат переводческой деятельности напрямую зависит от контекста знаний переводчика. При подборе правильного соответствия переводчику необходимо провести концептуальный анализ, классификацию объектов и событий, выбрать средства для репрезентации концептуального содержания оригинального текста.

Передавая содержание многозначного термина, переводчик основывается на прагматических, стилистических, когнитивных факторах. При подборе правильного переводческого эквивалента не всегда достаточно трансформировать поверхностные структуры исходного языка в структуры переводного языка, а необходимо провести глубинный анализ языковых соответствий многозначного слова, то есть определить содержательное ядро.

Цель статьи - охарактеризовать возможности когнитивного подхода при переводе многозначных терминологических единиц и верифицировать гипотезу о том, что полисемия терминов инвестиционной сферы связана с полисемией их общеупотребительных омонимов.

\section{Материал и методы}

Под терминосистемой понимается упорядоченное множество терминов, отношения между которыми отражают отношения между называемыми этими терминами понятиями. В центре нашего внимания находится терминосистема такой сферы экономической деятельности, как инвестирование. Источниками отбора терминов этой сферы послужили специализированные словари, отражающие инвестиционную деятельность, а также корпус текстов современного американского английского языка СОСА.

При выявлении содержательного ядра многозначного термина и терминов-синонимов авторами статьи применяется методика И.К. Архипова и С.В. Киселевой, основанная на положениях теории прототипов (см. о ней: [Архипов, 1998]). Так как лексикографические источники не всегда предлагают одинаковые дефиниции, проводится анализ значений терминов из нескольких словарей и определяется наиболее частотное значение. Далее рассматривается процесс семантического развития слова, поскольку диахронический анализ чрезвычайно важен при исследовании терминов [Temmerman, 2000, p. 229]. На следующем этапе происходит формирование когнитивного образа слова: проводится контекстуальный 
анализ, изучаются метафорические сравнения. На основании полученных результатов семантического анализа термина формулируется его содержательное ядро, которое обобщает все производные значения и демонстрирует их взаимосвязь [Киселева, 2009]. Предложенная методика позволяет смоделировать содержательную структуру термина и, как результат, принять правильное переводческое решение при выборе соответствия.

\section{Результаты и обсуждение}

Поскольку формулировка содержательного ядра - это результат выявления и сравнения большого количества лексикографических данных, то на первом этапе представляется необходимым извлечь то общее, что объединяет словарные дефиниции анализируемого термина. Представим лексикосемантическое описание инвестиционного термина dealer. Данный термин полисемантичен: специализированные словари терминов фиксируют у него два значения. Ядерные компоненты в словарных дефинициях выделены курсивом.

\section{Dealer:}

a) «1. an individual or firm willing to buy or sell securities for their own account; 2 . one who purchases goods or services for resale to consumers» (IDO) / 1. физическое лицо или фирма, желающие купить или продать иенные бумаги за свой счет; 2. тот, кто покупает товары или услуги для перепродажи потребителям (здесь и далее перевод наш. И. Р., С. К., М. М.);

b) «1. individual or firm acting as a principal in a securities transaction. Principals trade for their own account and risk; 2 . one who purchases goods or services for resale to consumers» (Downes, p. 135) / 1. физическое или юридическое лицо, выступающее в качестве принципала в сделке с ценными бумагами. Принципалы торгуют за свой счет и на свой риск; 2. тот, кто покупает товары или услуги для перепродажи потребителям;

c) «1. an individual or entity, such as a securities firm, when it acts as a principal and stands ready to buy and sell for its own account; 2 . more generally, an individual or entity which buys and sells products and holds an inventory» (IGIW) / 1. физическое или юридическое лицо, например фирма по ценнылм бумагам, когда оно выступает в качестве принципала и готово покупать и продавать за свой счет;
2. в более общем плане, физическое или юридическое лицо, которое покупает и продает товары и проводит инвентаризацию.

Как видно из представленных словарных определений, первое значение термина узкоспециализировано и связано с инвестиционной сферой. Дефиниция инвестиционного термина dealer ${ }_{1}$ включает характеристику покупаемого для перепродажи товара - ценных бумаг (securities), уточняет, кто именно покупает товар и несет финансовые риски: дилер проводит операции за свой собственный счет (own account). Данная информация является ключевой при переводе термина dealer в инвестиционных текстах. Второе значение этого термина dealer ${ }_{2}$ более общее, но именно оно приводится первым в словарях деловой и общеупотребительной лексики. В качестве примера ниже представлены дефиниции рассматриваемого слова, зафиксированные авторитетными лексикографическими изданиями. Курсивом выделены ядерные компоненты.

- Longman Dictionary of Contemporary English: «1. someone who buys and sells a particular type of goods; 2. as a company that sells a particular type of goods; 3 . someone whose job is buying and selling bonds, shares, currencies, etc on a financial market» (LDOCE) / 1. Кто-то, кто покупает и проdaem определенный вид товаров; 2. как компания, которая продает определенный вид товаров; 3. кого-то, чья работа заключается в покупке и продаже облигаций, акций, валют и т. д. на финансовом рынке;

- Cambridge Dictionary: «1. a person or company that buys and sells things for profit; 2. a person who gives out cards to players in a game» $(\mathrm{CD}) / 1$. человек или компания, которые покупают и продают вещи с целью получения прибыли; 2. человек, который раздает карты игрокам в игре;

- Collins Dictionary: «1. a person whose business involves buying and selling things; 2. someone who buys and sells illegal drugs» (COD) / 1. человек, чей бизнес связан с покупкой и продажей вещей; 2. тот, кто покупает и продает незаконные препараты.

Предложенные дефиниции иллюстрируют тот факт, что значение, приводимое словарями общей и деловой лексики под номером $1,-$ это и есть тот мысленный образ, возникающий у среднего носителя языка при восприятии слова dealer: 'someone buying and 
selling a particular product' / тот, кто покупает и продает определенный товар. В дефинициях под номером 3 дается уточнение значения, которое мы наблюдаем в специализированных инвестиционных словарях под номером 1. Так, в специализированных словарях терминов на первое место помещается дефиниция, отражающая более узкое, терминологическое значение слова.

Поскольку большинство определений терминов являются громоздкими и не подходят на роль содержательного ядра, представляется важным сузить набор семантических компонентов терминов до минимально необходимых. Работа по установлению общих сем позволила сформулировать содержательное ядро инвестиционного термина dealer: 'a person buying or selling financial products' / человек, покупающий или продающий финансовые продукты.

Как упомянуто выше, второй этап методики выявления содержательного ядра составляет систематизация сведений о происхождении слова и развитии его значений. В соответствии с данными этимологических словарей dealer образовано от deal, которое происходит из др.-англ. doelan «делить». Др.-англ. doelere «divider, distributor; agent, negotiator» / тот, кто делит, распределяет; агент, посредник. В процессе семантического развития лексической единицы dealer у нее сформировались следующие значения: «игрок, который раздает карты в игре» (1600 г.), «тот, чей бизнес - продавать и покупать товар регулярно, торговать» (1610 г.), «передавать другому как свою долю» (1300 г.), «поставщик наркотиков» (1920 г.) (Etymology). Дилер выполняет функцию агента / перекупщика / посредника, он работает с определенным видом товаров и теми покупателями, которые заинтересованы именно в этом товаре. Словари также выделяют категории дилеров, например: dealer at retail, dealer in goods, dealer in real estate, dealer in securities, art dealer / дилер в розничной торговле, дилер товаров, дилер недвижимости, дилер ценных бумаг, арт-дилер.

В древнеанглийском языке слово dealer обозначает посредника, связующее звено между Богом и людьми: «Іс wæs dcélere betwix Gode and eów» (Bosworth); отражает представления о том, что дилер - уважаемый человек:
«Đam wǽdlan gedafenap ðæt he gebidde for ðane dcélere» (Bosworth); он распределяет товары, посланные (данные) Богом: «God gesette ðone wélegan dcélere on his gódum» (Bosworth).

Словари среднеанглийского языка описывают дилера как человека, разделяющего и распределяющего; дающего милостыню: one who divides or distributes; a giver; one who gives alms; "Oure maker, oure keper, of alle oure godis natural, graciose and gloriose to vs a euer and a deler» (MEC).

По мере развития и усложнения товарно-денежных отношений лексическая единица dealer терминологизируется и становится синонимом слову trader «торговец», обозначая человека, который покупает товар оптом и перепродает его мелкими партиями. «Тhe Oxford English Dictionary» определяет dealer как «оne who sells articles in the same condition in which he has bought them: "He is supplied with horses by some dealer in Town"» (OED, p. 68) / тот, кто продает товары в том же состоянии, в каком он их купил: «Его снабжает лошадьми какой-то торговец в городе».

Таким образом, на парадигматическом уровне наблюдается сужение значения термина dealer с последующим закреплением в словарях инвестиционных терминов английского языка. При этом на уровне лексемы сужение значения приводит к расширению экстенсионала слова и, как следствие, к появлению дополнительных семантических вариантов.

Предлагая переводческие соответствия термина dealer, англо-русские словари инвестиционных терминов фиксируют следующие определения:

а) «дилер: юридическое лицо, выражающее готовность и желание покупать цеенные бумаги на свое имя (по своей предлагаемой цене) или продавать их от своего имени (по своей запрашиваемой цене)» (Perfekt.ru);

b) «дилер: 1. лицо, специализирующееся на определенном виде операщий с финансовыми активами либо на операциях с конкретным видом финансовых активов; 2. лицо, действующее как трейдер в операциях с какими-л. активами; 3. лицо, осуществляющее на профессиональной основе операции с финансовыми активами за свой счет» (Миркин, Миркин, с. 124);

c) «дилер: 1. компания или физическое лицо, которое оперирует на бирже (рынке) за собственный счет, т. е. как принципал, принимающий риск 
на себя; 2. сотрудник банка, специализирующийся на проведении конверсионных, депозитных и др. операций на финансовых рынках; 3. оптовый покупатель товаров и услуг для розничной перепродажи потребителям» (Федоров, т. 1, с. 390).

Переводческое соответствие dealer дилер не отражает тип и тематику текста (экономический, финансовый, инвестиционный), в котором обычно употребляется рассматриваемый инвестиционный термин. В связи с этим, чтобы избежать переводческих ошибок, переводчику, который специализируется на переводе финансовоинвестиционных текстов, необходимо принимать во внимание ту информацию энциклопедического характера, которая предложена в определении термина дилер в специализированных словарях. В этих определениях указывается на тип и место продажи продукта, предлагаемого инвестиционным дилером (ценные бумаги, финансовые активы, фондовая биржа).

В англоязычных текстах инвестиционной тематики специализация дилера также уточняется, например:

All bids - even those from Salomon Bros., the world's largest Treasury bond dealer - must be submitted in writing (COCA, USA Today 1990) / Bce заявки - даже от Salomon Bros., крупнейшего в мире дилера казначейских облигаций, - должны быть представлены в письменной форме;

The broker misidentified the West Coast underwriter, Montgomery Securities, as a dealer of penny stocks (COCA, USA Today 1991) / Брокер ошибочно опознал андеррайтера Западного побережья, Montgomery Securities, как дилера центовых акций;

A company, no matter what its business, calls itself a securities dealer and then marks down its customer receivables on the strength of the argument that they aren't marketable and some won't be paid (COCA, Forbes 1998) / Компания, независимо от ее бизнеса, называет себя дилером по ценным бумагам, а затем списывает дебиторскую задолженность своих клиентов на том основании, что они не продаются и некоторые из них не будут выплачены.

При исследовании вариантов перевода инвестиционного термина dealer было выявлено несколько переводческих решений. Например, термин dealer (с уточнением специфики продаваемого товара) переводится как торговец:
This sector includes banks, securities dealers, investment fund managers and certain insurance companies / Речь идет о банках, торговцах ценными бумагами, инвестиционных фондах и некоторых страховых учреждениях (Reverso Free...).

Предложенный вариант перевода является не совсем корректным, так как термин торговец (trader) выступает в инвестиционной сфере гиперонимом к термину дилер (dealer) и обозначает человека, который «продает и покупает финансовые продукты, товары или услуги за счет клиентов или за свой счет» (Федоров, т. 1, с. 700), в то время как дилер оперирует ценными бумагами только за свой счет.

В следующем примере представлено удачное переводческое решение, когда автор переводит термин dealer как учреждение, отталкиваясь от контекста и той информации, которая отражена в словарной дефиниции термина dealer, и утверждая, что дилером может быть не только физическое, но и юридическое лицо:

The Federal Banking Commission is the oversight authority for banks, stock exchanges, securities dealers and investment funds / Федеральная банковская комиссия является органом, контролирующим деятельность банков, бирж, учреждений, торгующих ценными бумагами, и инвестиционных фондов (Reverso Free...).

При осуществлении переводческой деятельности необходимо стремиться к точности, выразительности, разграничению понятий и использованию всего разнообразия ресурсов языка для передачи тонких оттенков мысли и чувств. Реализация этих задач неизбежно влечет за собой использование синонимов. Однако в одних контекстах синонимы могут быть взаимозаменяемы, в других их замена невозможна в силу несовместимости семантических признаков, когда, приравниваясь к доминанте синонимического ряда, синонимы все же отличаются от нее прагматическими добавками [Никитин, 2003, с. 141]. Мы разделяем мнение С.В. Гринева о том, что если слова обнаруживают даже незначительные смысловые различия, то они обозначают разные понятия и, как следствие, являются разными терминами [Гринев, 1990, с. 84]. 
Например, к настоящему времени произошла семантическая дифференциация инвестиционных терминов broker и agent, при этом данные термины остаются синонимами и могут взаимозаменяться при переводе. Так как некоторые словари определяют термин broker через термин agent, представляется необходимым исследовать их синонимические отношения. Рассмотрим словарные дефиниции терминов broker и agent с целью определения ядерных семантических компонентов. Ядерные семантические компоненты выделены курсивом.

Термин broker определяется следующим образом:

a) «1. an individual or firm that charges a fee or commission for executing buy and sell orders submitted by an investor; 2 . The role of a firm when it acts as an agent for a customer and charges the customer a commission for its services» (IDO) / 1. физическое лицо или фирма, которая взимает плату или комиссию за выполнение заказов на покупку и продажу, представленных инвестором; 2. роль фирмы, когда она выступает в качестве агента клиента и взимает с клиента комиссию за свои услуги;

b) «a person who acts as an intermediary between a buyer and seller, usually charging a commission. A broker who specializes in stocks, bonds, commodities, or options acts as agent and must be registered with the exchange where the securities are traded» (Downes, p. 67) / лицо, которое выступает в качестве посредника между покупателем и продавиом, обычно взимает комиссию. Брокер, специализирующийся на акциях, облигациях, товарах или опционах, выступает в качестве агента и должен быть зарегистрирован на бирже, где продаются ценные бумаги;

c) «An individual or firm which acts as an intermediary between a buyer and seller, usually charging a commission. For securities and most other products, a license is required» (IGIW) / Физическое лицо или фирма, которая выступает в качестве посредника между покупателем и продавиом, обычно взимая комиссию. Для ценных бумаг и большинства других продуктов требуется лицензия;

d) «1. a dealer who acts as a middleman between a buyer and a seller; 2. (stock)broker - a person or firm that buys and sells shares or bonds on behalf of clients» (Collin, p. 44) / 1. дилер, который выступает в качестве посредника между покупателем и продавиом; 2. (биржевой) брокер - лицо или фирма, которая покупает и продает акции или облигации от имени клиентов.
Представленные дефиниции показывают, что в инвестиционной терминологии brokerэто лицо, предоставляющее услуги посредника в инвестиционно-финансовой сфере на основании лицензии и получающее вознаграждение за помощь в осуществлении операций с инвестиционными продуктами. Брокер обладает полномочиями заключать сделку от своего имени, но работает не за свой счет, а за счет клиента. Брокер выступает в роли агента для клиента и оказывает помощь, получая за это комиссию. Ядерные компоненты выделены курсивом.

Термин agent определяется следующим образом:

a) «individual authorized by another person, called the principal, to act in the latter's behalf in transactions involving a third party» (Downes, p. 17) / физическое лицо, уполномоченное другим лицом, называемым принципалом, действовать от имени последнего в сделках с участием третьей стороны;

b) «an individual or firm authorized to act on behalf of another (called the principal), such as by executing a transaction or selling and servicing an insurance policy» (IGIW) / физическое лицо или фирма, уполномоченные действовать от другого лица (называемого принципалом), например, путем совершения сделки или продажи и обслуживания страхового полиса;

c) «1. an individual or firm that places securities transactions for clients; 2 . a person licensed by a state to sell insurance; 3. a securities salesperson who represents a broker-dealer or issuer when selling or trying to sell securities to the investing public. Essentially, this is the person who makes a transaction on behalf of his or her employer or client» (IDO) / 1. физическое лицо или фирма, которая осуществляет операции с ценными бумагами для клиентов; 2. лицо, имеющее государственную лицензию на продажу страхования; 3 . продавец ценных бумаг, который представляет брокера-дилера или эмитента при продаже или попытке продать ценные бумаги инвестирующей общественности. По сути, это лицо, которое совершает сделку от имени своего работодателя или клиента.

Таким образом, агент - это лицо, обладающее правом действовать от имени принципала (клиента, руководителя) в обмен за вознаграждение, не подвергаясь при этом финансовым рискам. Функция агента - помочь клиенту в проведении транзакции. Актуализация в определениях термина agent 
таких сем, как 'authorized by', 'to act on behalf of', 'represent' / 'уполномочен', 'действовать от имени', 'представлять', позволяет говорить об отличиях агента от брокеpa: агент действует от имени и в интересах определенной компании, он может быть сотрудником организации и в этом случае получать вознаграждение от работодателя за свою работу. Брокер - независимый эксперт, который осведомлен о финансово-инвестиционных продуктах различных компаний, действует в интересах клиента и получает вознаграждение от него. Кроме того, для ведения посреднической деятельности брокер обязан иметь лицензию. Этот факт подтверждается словарными определениями термина broker: «must be registered» (Downes, p. 67) / должен быть зарегистрирован; «a license is required» (IGIW) / необходима лицензия. Помимо роли посредника, брокер выполняет функцию консультанта для клиента, в то время как агент представляет интересы своей компании либо тех компаний, с которыми его работодатель заключил соглашение: «an agent typically represents a company and is trained on the products and services offered by the company, while a broker is considered as a representative of the customer and his service apart from being that of a middle man in a transaction is one of consultation» (FTD) / агент, как правило, представляет компанию и обучается продуктам и услугам, предлагаемым компанией, в то время как брокер рассматривается как представитель клиента, и его услуги в сделке являются консультацией. Тем не менее термины broker и agent синонимичны, так как и брокер, и агент выступают посредниками между продавцом и покупателем: «an agent or broker acts as intermediary between buyer and seller, taking no financial risk personally or as a firm, and charging a commission for the service» (Downes, p. 16) / агент или брокер выступает в качестве посредника между покупателем и продавцом, не принимая на себя никаких финансовых рисков лично или как фирма и взимая комиссию за услугу.

Факт синонимичности терминов broker и agent и наличия у них общего содержательного ядра ('a middleman'/ 'intermediary', 'representative' - 'посредник'/'представитель') подтверждается тем, что:

1) в словарных определениях зафиксированы общие семантические компоненты ('act on behalf of', 'sell to smb', 'for clients' / 'действовать от имени', 'продавать кому-либо', 'для клиентов');

2) в контекстах термин agent поясняется термином broker:

The return for an investor buying funds through a sales agent (such as a bank or broker) was 113 percent (COCA, Washington Post 1996) / Прибыль для инвестора, покупающего средства через торгового агента (такого как банк или брокер), составила 113 процентов;

3) в контекстах термин broker поясняется термином agent:

A broker who specializes in stocks, bonds, commodities, or options acts as agent and must be registered with the exchange where the securities are traded (Downes, p. 67) / Брокер, специализирующийся на акциях, облигациях, товарах или опционах, выступает в качестве агента и должен быть зарегистрирован на бирже, где торгуют ценными бумагами;

4) термин broker может переводиться словом посредник:

a) UNDP was perceived from the outset primarily as a broker of funding and technical cooperation to support developing countries / С самого начала ПРООН задумывалась главным образом как посредник в вопросах финансирования и технического сотрудничества в целях поддержки развивающихся стран (Reverso Free...);

b) That notwithstanding, the final determination or assignation of the transacted instruments to a specific beneficiary client will always be made by the securities broker in the case of transactions carried out on the orders of various clients or of their portfolio managers / Без ущерба для этого, окончательное определение или присвоение передаваемых документов определенному клиенту-получателю во всех случаях осуществляется посредником по работе с ценными бумагами, если такие операции осуществляются с целью выполнения распоряжений клиентов или управляющих портфелями ценных бумаг (Reverso Free...);

5) термин agent может переводиться словом посредник: 
a) The issue may also arise when an agent acts for a principal / Этот вопрос может возникнуть и в том случае, когда посредник выступает от имени принципала (Reverso Free...);

b) HYIP is an agent between a private investor who does not have possibilities and knowledge to effectively play on the market fluctuations and high yield economic formations / HYIP - это посредник между частным инвестором, не имеющим возможностей и познаний для эффективной игры на рыночных колебаниях, и высокодоходными экономическими образованиями (Reverso Free...).

\section{Выводы}

Такая особенность инвестиционного текста, как относительная конкретизированность, способствует ситуационной стандартизации и последующему формированию терминологии. Результаты, полученные в ходе исследования многозначного термина инвестиционной сферы, позволили доказать гипотезу о том, что его полисемия связана с полисемией его общеупотребительных омонимов. Термины английского языка, отражающие инвестиционную сферу, также как и термины других областей деятельности и специальных знаний, образуются семантическим способом от многозначных общеупотребительных слов путем терминологизации одного из значений полисемантичного слова. Тот факт, что термины имеют однозначные соответствия в языке перевода, способствует более точной передаче смысла при осуществлении переводческой деятельности. Основная функция переводчика заключается в адекватной передаче когнитивной информации, заложенной в исходном тексте. Выполнение данной задачи в полном объеме возможно главным образом благодаря грамотному использованию когнитивного контекста и правильному определению содержательного ядра терминологической единицы.

\section{СПИСОК ЛИТЕРАТУРЫ}

Алексеева Л. М., 2006. Стратегии удачного перевода // Индустрия перевода и информационное обеспечение внешнеэкономической деятельности предприятий : материалы Междунар. конф. (Пермь, 5-7 дек. 2006 г.). Пермь : Изд-во Перм. гос. тех. ун-та. С. 8-12.
Архипов И. К., 1998. Проблема языка и речи в свете прототипической семантики // Studia linguistica. Вып 6 : Проблемы лингвистики и методики преподавания иностранных языков. С. 5-22.

Болдырев Н. Н., 2018. Перевод как проблема выбора когнитивных доминант // Когнитивные исследования языка. № 34 : Cognitio и Communicatio в современном глобальном мире. С. 33-37.

Бурдина О. Б., 2021. Когнитивные основы моделирования терминологии в профессиональном дискурсе // Когнитивные исследования языка. № 3 (46) : Язык и мышление в эпоху глобальных перемен. С. 841-844.

Воюцкая А. А., 2018. Объективные и субъективные различия в подходах к принятию переводческого решения // Когнитивные исследования языка. № 34 : Cognitio и Communicatio в современном глобальном мире. С. 853-857.

Галактионова М. А., 2021. Метафорическое терминообразование: когнитивный язык науки // Когнитивные исследования языка. № 3 (46) : Язык и мышление в эпоху глобальных перемен. С. 844-848.

Гринев С. В., 1990. Основы лексикографического описания терминосистем : дис. ... д-ра филол. наук. М. 436 c.

Киселева С. В., 2009. Сущность многозначного слова в английском языке. СПб. : Астерион. 216 с.

Киселева С. В., 2010. Когнитивные аспекты многозначного слова // Когнитивные исследования языка. № 6 : Международный конгресс по когнитивной лингвистике. С. 306-308.

Колесников В. В., 2018. О моделировании содержательной структуры текста при переводе // Когнитивные исследования языка. № 34 : Cognitio и Communicatio в современном глобальном мире. С. 867-870.

Миронова М. Ю., Киселева С. В., 2020а. Структурносемантические характеристики инвестиционной английской терминологии. СПб. : Изд-во СПбГЭУ. $125 \mathrm{c.}$

Миронова М. Ю., Киселева С. В., 2020б. Метафтонимия в английском языке (на примере инвестиционных терминов) // Язык и культура в эпоху глобализации : сб. науч. ст. по материалам Первой Всерос. (нац.) науч. конф. с междунар. участием (Санкт-Петербург, 30-31 окт. 2020 г.) / под ред. И. В. Кононовой. СПб. : Изд-во СПбГЭУ. Вып. 1.С. 64-72.

Никитин М. В., 2003. Что рисуют нам «картины мира»? // Известия Российского государственного педагогического университета им. А.И. Герцена. Т. 3, № 5. С. 141-148.

Руберт И. Б., 1998. Текст в синхронии и диахронии. Эволюционные аспекты жанров. СПб. : Академпринт. 62 с. 
Temmerman R, 2000. Towards New Ways of Terminology Description. The Sociocognitive Approach. Amsterdam : John Benjamins Publishing Co. 276 p.

\section{ИСТОЧНИКИ И СЛОВАРИ}

Миркин, Миркин - Миркин Я. М., Миркин В. Я. Англо-русский толковый словарь по банковскому делу, инвестициям и финансовым рынкам. Свыше 10000 терминов. М. : Альпина Бизнес Букс, 2006. 422 с.

Федоров - Федоров Б. Г. Новый англо-русский банковский и инвестиционный энциклопедический словарь : в 2 т. СПб. : Лимбус Пресс : К. Тублина, 2011. Т. 1.912 с. ; Т. 2.832 с.

Bosworth - Bosworth J.An Anglo-Saxon Dictionary Based on the Manuscript Collections of the Late Joseph Bosworth. URL: http://www.bosworthtoller.com (date of access: 28.02.2020).

$C D$ - Cambridge Dictionaries Online. URL: http:// dictionary.cambridge.org (date of access: 28.02.2020).

COD - Collins Online Dictionary. URL: http:// collinsdictionary.com (date of access: 28.02.2020).

Collin-Collin P.H. Dictionary of Banking and Finance. $3^{\text {rd }}$ ed. L. : Bloomsbury, 2003. 383 p.

COCA - Corpus of Contemporary American English. URL: http://corpus.byu.edu/coca/ (date of access: 02.03.2020).

Downes - Downes J. Dictionary of Finance and Investment Terms. $5^{\text {th }}$ ed. Hauppauge, N. Y. : Barron's, cop. 1998. 730 p.

Etymology - Online Etymology Dictionary. URL: www.etymonline.com (date of access: 28.02.2020).

$I G I W$ - Investing Glossary Investor Words. URL: http:// www.investorwords.com (date of access: 02.03.2020).

IDO - Investment Dictionary Online. URL: http:// investmentterms.net (date of access: 02.03.2020).

FTD - Financial Terms Dictionary. URL: http://www. investopedia.com (date of access: 02.03.2020).

LDOCE - Longman Dictionary of Contemporary English. URL: https://www.ldoceonline.com/ dictionary/dealer (date of access: 02.03.2020).

MEC - Middle English Compendium. URL: https:// quod.lib.umich.edu/m/middle-english-dictionary/ dictionary/MED830 (date of access: 28.02.2020).

$O E D$ - Murray J. The Oxford English Dictionary. In 20 Vols. Vol. 4. Oxford : Oxford University Press, $1989.532 \mathrm{p}$.

Perfect.ru - Perfect.ru. Толковый англо-русский инвестиционный словарь. URL: http://www. perfekt.ru/dictionaries/invest/i.html (date of access: 02.03.2020).
Reverso Free... - Reverso Free Online Translation : dictionary. URL: http://context.reverso.net/ (date of access: 02.03.2020).

\section{REFERENCES}

Alekseeva L.M., 2006. Strategii udachnogo perevoda [Strategies of Successful Translation]. Industriya perevoda i informatsionnoe obespechenie vneshneekonomicheskoy deyatelnosti predpriyatiy: materialy Mezhdunar. konf. (Perm, 5-7 dek. 2006 g.) [Translation Industry and Information Support of Foreign Economic Activity of Enterprises. Proceedings of the International Conference (Perm, December 5-7, 2006)]. Perm, Izd-vo Permskogo gosudarstvennogo tekhnicheskogo universiteta, pp. 8-12.

Arkhipov I.K., 1998. Problema yazyka i rechi v svete prototipicheskoy semantiki [The Problem of Language and Speech in the Light of Prototypical Semantics]. Studia linguistica, iss. 6, pp. 5-22.

Boldyrev N.N., 2018. Perevod kak problema vybora kognitivnykh dominant [Translation As a Cognitive Problem of the Dominants Choice]. Kognitivnye issledovaniya yazyka [Cognitive Studies of Language], no. 34, pp. 33-37.

Burdina O.B., 2021. Kognitivnye osnovy modelirovaniya terminologii v professionalnom diskurse [Cognitive Bases of Terminology Modeling in Professional Discourse]. Kognitivnye issledovaniya yazyka [Cognitive Studies of Language], no. 3 (46), pp. 841-844.

Voyutskaya A.A., 2018. Obyektivnye i subyektivnye razlichiya $\mathrm{v}$ podkhodakh $\mathrm{k}$ prinyatiyu perevodcheskogo resheniya [Objective and Subjective Differences in Approaches to Making a Translation Decision]. Kognitivnye issledovaniya yazyka [Cognitive Studies of Language], no. 34, pp. 853-857.

Galaktionova M.A., 2021. Metaforicheskoe terminoobrazovanie: kognitivnyy yazyk nauki [Metaphorical Term Formation: The Cognitive Language of Science]. Kognitivnye issledovaniya yazyka [Cognitive Studies of Language], no. 3 (46), pp. 844-848.

Grinev S.V., 1990. Osnovy leksikograficheskogo opisaniya terminosistem: avtoref. dis. ... d-ra. filol. nauk [Fundamentals of Lexicographic Description of Term Systems. Dr. philol. abs. sci. diss.]. Moscow. $436 \mathrm{p}$.

Kiseleva S.V., 2009. Sushchnost mnogoznachnogo slova $v$ angliyskom yazyke [The Essence of a Polysemantic Word in English]. Saint Petersburg, Asterion Publ. 216 p. 
Kiseleva S.V., 2010. Kognitivnye aspekty mnogoznachnogo slova [Cognitive Aspects of a Polysemantic Word]. Kognitivnye issledovaniya yazyka [Cognitive Studies of Language], no. 6, pp. 306-308.

Kolesnikov V.V., 2018. O modelirovanii soderzhatel'noy struktury teksta pri perevode [On Modeling the Content Structure of the Text in Translation]. Kognitivnye issledovaniya yazyka [Cognitive Studies of Language], no. 34, pp. 867-870.

Mironova M.Yu., Kiseleva S.V., 2020a. Strukturnosemanticheskie kharakteristiki investitsionnoy angliyskoy terminologii [Structural and Semantic Characteristics of Investment English Terminology]. Saint Petersburg, Izd-vo SPbGEU. $125 \mathrm{p}$.

Mironova M.Yu., Kiseleva S.V., 2020b. Metaftonimiya $\mathrm{V}$ angliyskom yazyke (na primere investitsionnykh terminov) [Metaphtonymy in English (By the Example of Investment Terms)]. Kononova I.V., ed. Yazyk i kultura $v$ epokhu globalizatsii: sb. nauch. st. po materialam Pervoy Vseros. (nats.) nauch. konf. s mezhdunar. uchastiem (SanktPeterburg, 30-31 okt. $2020 \mathrm{~g}$. [Language and Culture in the Era of Globalization. Collection of Scientific Articles on the Materials of the $1^{\text {st }}$ All-Russian (National) Scientific Conference with International Participation (Saint Petersburg, October 30-31, 2020)]. Saint Petersburg, Izd-vo SPbGEU, iss. 1, pp. 64-72.

Nikitin M.V., 2003. Chto risujut nam «kartiny mira»? [What Do the "Pictures of the World" Draw for Us?]. Izvestiya Rossiyskogo gosudarstvennogo pedagogicheskogo universiteta im. A.I. Gertsena [Izvestia: Herzen University Journal of Humanities \& Sciences], vol. 3, no. 5, pp. 141-148.

Rubert I.B., 1998. Tekst v sinkhronii $i$ diakhronii. Evoliutsionnye aspekty zhanrov [Text in Synchrony and Diachrony. Evolutionary Aspects of Genres]. Saint Petersburg, Akademprint Publ. 62 p.

Temmerman R., 2000. Towards New Ways of Terminology Description. The Sociocognitive Approach. Amsterdam, John Benjamins Publishing Co. $276 \mathrm{p}$.

\section{SOURCES AND DICTIONARIES}

Mirkin, Ya.M., Mirkin V.Ya. Anglo-russkiy tolkovyy slovar po bankovskomu delu, investiciyam $i$ finansovym rynkam. Svyshe 10000 terminov [English-Russian Dictionary of Banking, Investment and Financial Markets. Over 10,000 Terms]. Moscow, Al'pina Biznes Buks Publ., 2006. 422 p.

Fedorov B.G. Novyy anglo-russkiy bankovskiy $i$ investicionnyy enciklopedicheskiy slovar: v 2 t. [New English-Russian Banking and Investment Encyclopedic Dictionary. In 2 Vols.]. Saint Petersburg, Limbus Press Publ., K. Tublina Publ., 2011, vol. 1.912 p.; vol. 2. 832 p.

Bosworth J. An Anglo-Saxon Dictionary Based on the Manuscript Collections of the Late Joseph Bosworth. URL: http://www.bosworthtoller.com (accessed 28 February 2020).

Cambridge Dictionaries Online. URL: http:// dictionary.cambridge.org (accessed 28 February 2020).

Collins Online Dictionary. URL: http:// collinsdictionary.com (accessed 28 February 2020).

Collin P.H. Dictionary of Banking and Finance. London, Bloomsbury, 2003. 383 p.

Corpus of Contemporary American English. URL: http://corpus.byu.edu/coca (accessed 2 March 2020).

Downes J. Dictionary of Finance and Investment Terms. Hauppauge, New York, Barron's, cop. $1998.730 \mathrm{p}$.

Online Etymology Dictionary. URL: www. etymonline.com (accessed 28 February 2020).

Investing Glossary Investor Words. URL: http://www. investorwords.com (accessed 2 March 2020).

Investment Dictionary Online. URL: http:// investmentterms.net (accessed 2 March 2020).

Financial Terms Dictionary. URL: http://www. investopedia.com (accessed 2 March 2020).

Longman Dictionary of Contemporary English. URL: https:/www.ldoceonline.com/dictionary/dealer (accessed 2 March 2020).

Middle English Compendium. URL: https:/quod. lib.umich.edu/m/middle-english-dictionary/ dictionary/MED830 (accessed 28 February 2020).

Murray J. The Oxford English Dictionary. In 20 Vols. Vol. 4. Oxford, Oxford University Press, 1989. $532 \mathrm{p}$.

Perfect.ru. Tolkovyy anglo-russkiy investitsionnyy slovar' [English-Russian Explanatory Investment Dictionary]. URL: http://www.perfekt.ru/ dictionaries/invest/i.html (accessed 2 March 2020).

Reverso Free Online Translation. Dictionary. URL: http://context.reverso.net (accessed 2 March 2020). 
И.Б. Руберт, С.В. Киселева, М.Ю. Миронова. Перевод многозначных и синонимичных терминов

\section{Information About the Authors}

Irina B. Rubert, Doctor of Sciences (Philology), Professor, Department of English Philology and Translation, Saint Petersburg State University of Economics, Griboedov Channel Emb., 30-32, 191023 Saint Petersburg, Russia, irleru@mail.ru, https://orcid.org/0000-0002-5041-7977

Svetlana V. Kiseleva, Doctor of Sciences (Philology), Associate Professor, Department of English Philology and Translation, Saint Petersburg State University of Economics, Griboedov Channel Emb., 30-32, 191023 Saint Petersburg, Russia, svkiseljeva@bk.ru, https://orcid.org/0000-0002-3814-1111

Marina Yu. Mironova, Candidate of Sciences (Philology), Department of the English Language No. 2, Saint Petersburg State University of Economics, Griboedov Channel Emb., 30-32, 191023 Saint Petersburg, Russia, mkpr@yandex.ru, https://orcid.org/0000-0002-7938-6254

\section{Информация об авторах}

Ирина Борисовна Руберт, доктор филологических наук, профессор кафедры английской филологии и перевода, Санкт-Петербургский государственный экономический университет, наб. канала Грибоедова, 30-32, 191023 г. Санкт-Петербург, Россия, irleru@mail.ru, https:/orcid.org/0000-0002-5041-7977

Светлана Владимировна Киселева, доктор филологических наук, доцент, профессор кафедры английской филологии и перевода, Санкт-Петербургский государственный экономический университет, наб. канала Грибоедова, 30-32, 191023 г. Санкт-Петербург, Россия, svkiseljeva@bk.ru, https://orcid.org/0000-0002-3814-1111

Марина Юрьевна Миронова, кандидат филологических наук, доцент кафедры английского языка № 2, Санкт-Петербургский государственный экономический университет, наб. канала Грибоедова, 30-32, 191023 г. Санкт-Петербург, Россия, mkpr@yandex.ru, https://orcid.org/0000-0002-7938-6254 